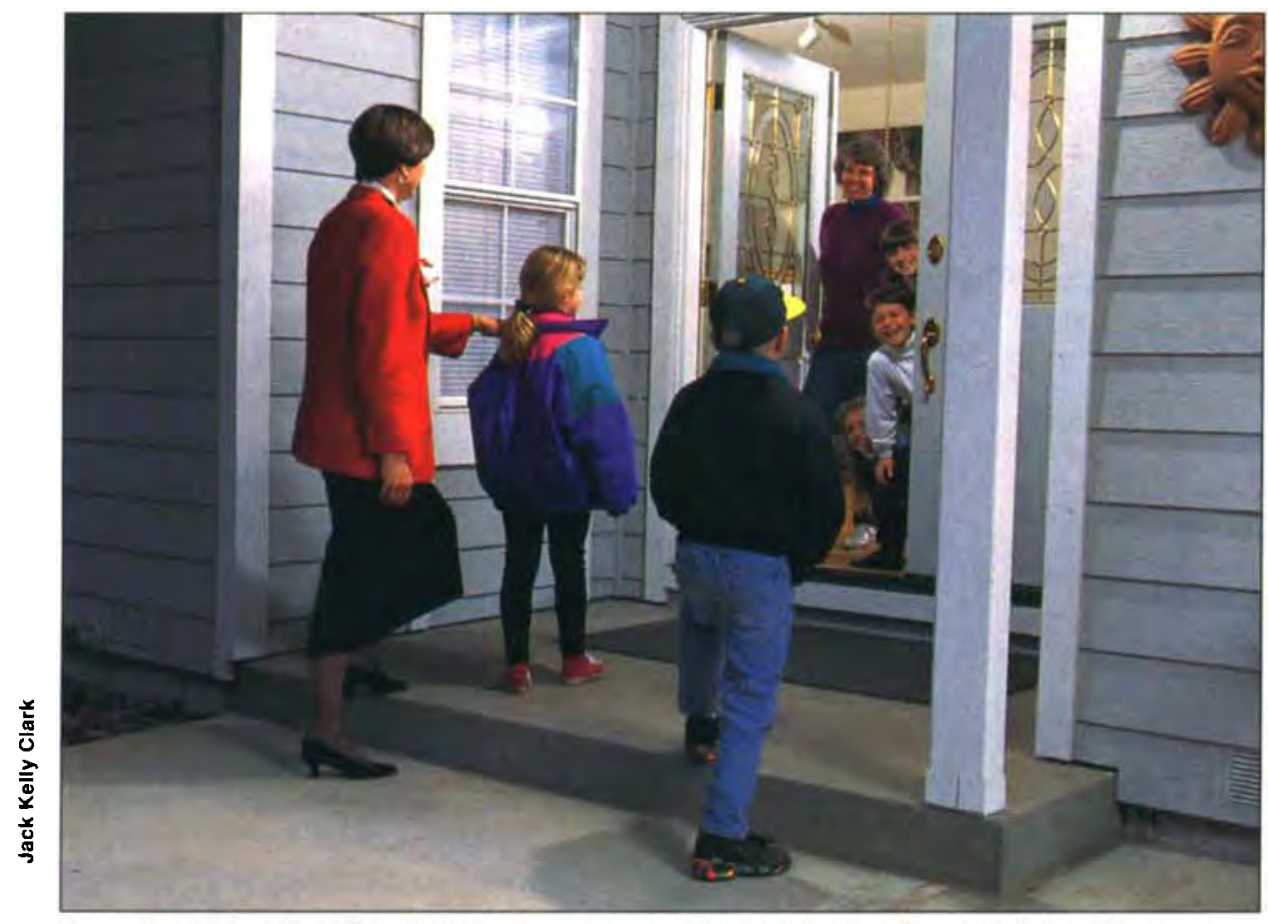

Dropping kids off at day care is more commonplace as increasing numbers of women join the workforce.

\title{
Does mothering school-age children mix with paid employment?
}

Brenda K. Bryant

$S$ ixty-nine percent of mothers with school-age children and adolescents are in the work force. What impact does maternal employment have on parenting and child development during these years? This analysis uses a selective review of the literature to characterize the dimensions of a comprehensive answer.

First, it is clear that maternal investment in work does not preclude an investment in parenting. While it would be easy to report, as have others, that research indicates maternal employment does not have any clear effects on child development, this technically correct statement is misleading ( see sidebar, reference \#1, p. 24).

Does a mother's employment impact on parenting and child development? The answer is most definitely "yes" and the consequences can be positive and/or negative. Can a mother's lack of employment impact on parenting and child development?
Again the answer is most definitely "yes;" and the consequences again can be positive and/or negative.

The impact of maternal employment must be explored in terms of "proximal" factors, which are those factors children experience directly. Research fails to document clear and consistent effects of maternal employment on child development, indicating there is a dynamic interplay between the varying conditions of maternal employment and the immediate experiences of children in their daily lives. Maternal employment can have an impact, good or bad, on the kinds of proximal factors that are important to a child's development.

To understand the role maternal employment plays in the development of school-age children (grades 1-12), several issues must be assessed. These include the role economics plays in the decision of parental employment, whether "family-friendly" policies

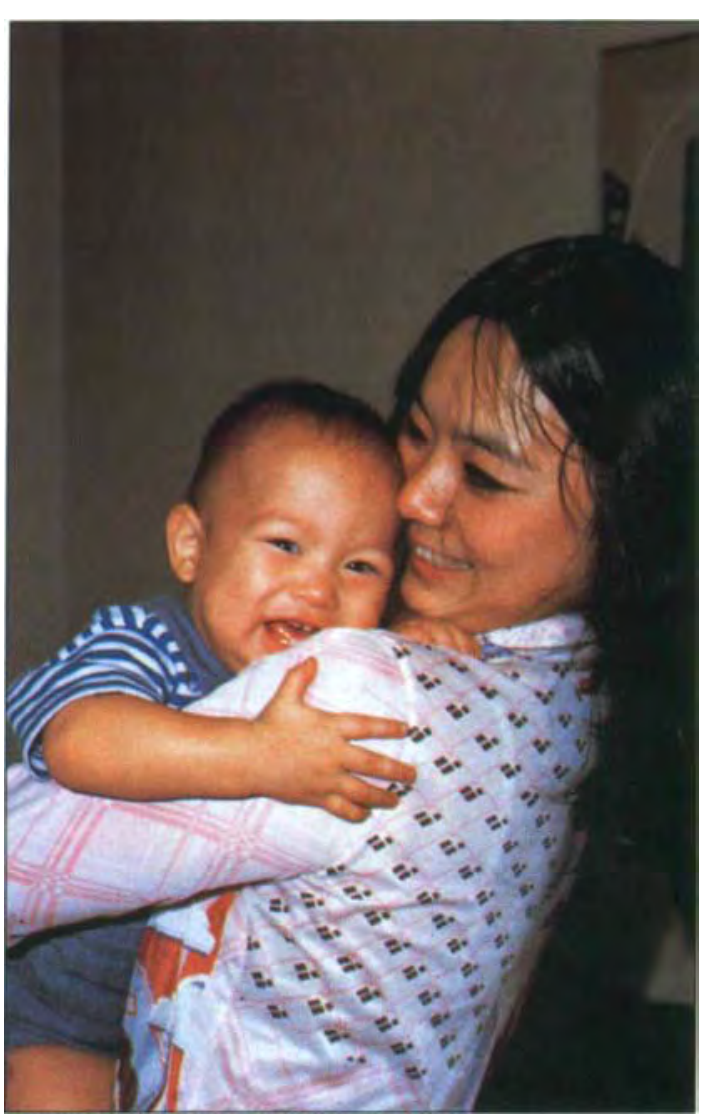

Does working outside the home preclude an investment in parenting? Not if parents respond to children's specific needs. 


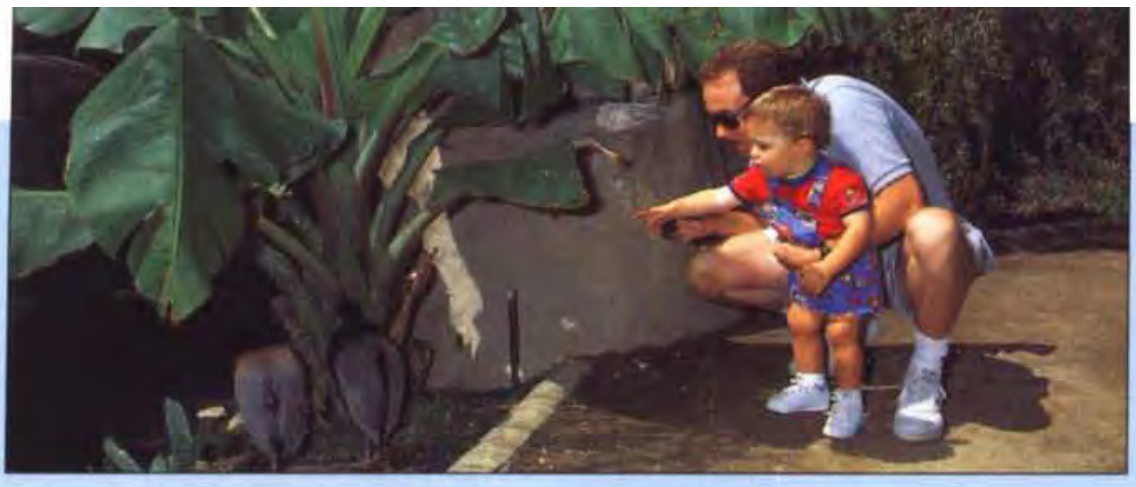

\section{Notes for further reading}

As editorial policy, California Agriculture devotes its limited space to developing a meaningful interpretation of technical research; it does not print extensive literature citations. However, because the accompanying article reviews the work of 42 developmental psychologists and sociologists, and because readers may wish to pursue avenues of this research, we include the following abbreviated list of references which corresponds to major findings cited in the text. Each numbered item lists the author(s), publication year(s) and journal or book to which the matching note in the text refers. For a complete reference list, contact Brenda Bryant at (916) 752-2242.

\section{References}

1. Matthews, K.A., \& Rodin, J. 1989. American Psychologist.

Greenberger, E., \& Goldberg, W. 1989. Developmental Psychology.

D'Amico, R.J.; Haurin, R.J.; \& Mott, F.L. 1983. Children of working parents: Experiences and outcomes.

Gottfried, A.E. 1991. Employed mothers and their children.

Hoffman, L.W. 1988. Maternal employment and children's development: Longitudinal research.

Richards, M.H., \& Duckett, E. 1991. Employed mothers and their children.

2. Bronfenbrenner, U. 1977. American Psychologist.

Parke, R. 1978. Children and the environment.

3. Conger, R.D.; Conger, K.J.; Elder, G.H.; Lorenz, F.O.; Simons, R.L.; \& Whitbeck, L.B. 1992. Child Development.

4. Hoffman, L.W. 1974. Developmental Psychology.

5. Gold, D., \& Andres, D. 1978. Child Development.

Hoffman, L.W. 1974. Developmental Psychology.

Hoffman, L.W. 1979. American Psychologist.

6. Moorehouse, M.J. 1991. Developmental Psychology.

7. Montemayor, R. 1984. Journal of Youth \& Adolescence.

8. Bryant, B.K. 1992. Family-peer relationships: Modes of linkage.
9. Robinson, B.E.; Rowland, B.H.; \& Coleman, M. 1986. Latchkey kids.

10. Belle, D. 1994. Social networks and social support in childhood and adolescence.

Robinson, B.E.; Rowland, B.H.; \& Coleman, M. 1986. Latchkey kids.

11. Steinberg, L. 1986. Developmental Psychology.

12. Wallston, B. 1973. Journal of Child Psychology \& Psychiatry \& Allied Disciplines.

13. Crouter, A.C., \& Crowley, M.S. 1990. Journal of Early Adolescence.

Hoffman, L.W. 1974. Developmental Psychology.

Montemayor, R. 1984. Journal of Youth \& Adolescence.

14. Pleck, J.H. 1985. Working wives/ working husbands.

15. Benin, M., \& Chong, Y. 1993. The employed mother and the family context.

Pleck, J.H. 1985. Working wives/ working husbands.

16. Pittman, J.F., \& Kerpelman, J.L. 1993. The employed mother and the family context.

17. Piotrkowski, C.S., \& Gornick, L.K. 1987. The psychology of separation and loss: Perspectives on development, life transitions, and clinical practice.

18. Bryant, B.K. 1993. Proceedings of Western Region Home Management and Family Economics Educators Conference. exist in the workplace and at school, the involvement of both parents in the parenting arena at home, and the child's experience during after-school hours. A multicontextual analysis is useful, one that recognizes the impact of features of the immediate family environment as well as that of the wider physical and social context in which the child and parent function, including, but not limited to, parents' workplace (sidebar, \#2).

\section{An economic issue}

Any discussion of maternal employment and its impact on parenting and child development during the school-age years must first recognize that for many, maternal employment is an economic necessity. For these women, maternal employment eliminates or reduces economic distress, a form of family stress that can impact negatively on both parenting and child development. In general, economic distress has been found to lead to parental depression, marital conflict, and disruption in skillful parenting; this disruption in parenting skill has adverse consequences on child development (sidebar, \#3). It is not the economic adversity per se that has the negative impact, but rather the disruption and conflict that it causes in marital relations and parent-child relations that can negatively affect a child.

Studies of families in lower socioeconomic situations have documented that employed mothers are more likely than their unemployed counterparts to provide structured rules for their children and have consistency between theory and practice (sidebar, \#4). If economic distress impacts negatively on parenting, and maternal employment can reduce this distress, maternal employment then can be beneficial to both parenting and child development.

Putting aside the issue of economic distress, discussions are often framed as though there is an absolute "yes" or "no" answer to the question of whether mothers should work for pay when considering the good of their children. Research on family functioning and child development suggests that such polarization of thinking is 
unwarranted. Working and not working both generate potential problems for parenting and child development. While parental absence is seen as the crux of the potential problem for working mothers, the need to live vicariously through their children and prohibit a child's emerging autonomy is viewed as a potential problem of maternal

nonemployment.

Findings to date suggest that mothers who work fulltime and mothers who do not work all show some degree of distress in their parent-child relationships.

Studies have indicated that mothers who do not work for pay may over-invest in the mother role because it is the only one from which they derive a sense of selfworth (sidebar, \#5). At the same time, mothers who work full-time often feel guilty about being physically unavailable. Research shows that young school-age children whose mothers work full-time demonstrate a clear need to spend time with their mother in shared pleasurable activities (sidebar, \#6). Adolescent males (but not females), have been shown to have longer, more frequent, and more intense arguments with mothers who worked (sidebar, \#7). Clearly, both employment and nonemployment bring risks to the developmental processes in children. A better way to frame the discussion of maternal employment and children's development would be to address issues such as the availability of working mothers to their children and the potential overinvestment of the nonemployed mother in her children's dependency.

\section{No firm list for quality parenting}

The factors that children experience directly are what appear to matter most to a child's development. A fulltime employed mother's ability to engage her young school-age child in enjoyable activities appears to be an important proximal, family factor that benefits children's social and cognitive

functioning at school. In a study of the impact of maternal parenting on child development and school competence, M.J. Moorehouse (sidebar, \#6) found that when mothers increase their employment commitments to full-time or sustain long work hours on a stable basis, both the facilitative effects of shared mother-child activities and the detrimental effects of infrequent mother-child activities appear to be accentuated among young school-age children. Full-time employed mothers who were not able to share enjoyable activities with their entry-level school children were more likely to have children who did not function as well cognitively and socially as did children whose mothers worked part-time or not at all.

This link between frequency of enjoyable activities with one's mother and school achievement and adjustment existed only for children of fulltime working mothers and was especially strong for children whose mothers had recently increased their employment commitment to full time. These findings, in effect, serve to remind us that quality parenting is not a list of specific "do's" and "don'ts" that guarantee certain benefits for children. Good parenting strategies are effective when they address children's specific needs, and not all children have the same needs.

Consistent with this notion is the finding that children whose mothers were not employed appeared to benefit from opportunities to engage with peers away from direct adult supervision, while children whose mothers worked full-time benefited from group activities in which there was direct adult supervision (sidebar, \#8). Stated another way, children of both working and nonworking mothers experienced activities with and without adult supervision, but these experiences operated differently for the two groups of children.

For working mothers, children's need for adult supervision is clear. Children need after-school care (sidebar, \#9), but just how this adult guidance ought to be effected is not so evident. It is becoming evident that a variety of after-school arrangements can work well. Even self-care can be managed well by children in certain circumstances. Research indicates few or no differences in the social and cognitive development of self-care children when compared to children in adult-monitored care arrangements (sidebar, \#10). Self-care does not mean that adult monitoring is not present. Children who have rules and routines 
to follow while at home (e.g., no TV viewing unless homework is completed) fare much better than children who are left unsupervised without such rules and routines (sidebar, \#11).

It is important to note that there are many ways in which maternal employment status is unrelated to many aspects of parenting. First, employment per se has been found to be unrelated to child-rearing patterns and to summary measures of the adequacy of mothering (e.g., limit-setting, sensitivity to the child's needs, warmth) among equally educated, two-parent, white families (sidebar, \#12). Second, only moderate adjustment or no adjustment by fathers has been documented (sidebar, \#13). Fathers seem to take on slightly more child care tasks when wives are employed (sidebar, \#14), but mothers remain primarily responsible for ensuring that children have adequate child care (sidebar, \#15). The increase in paternal involvement rarely matches the wife's shift in employment status and concomitant need for accommodations in family workload. Finally, family tasks such as managing unexpected child care needs such as those of a sick child typically fall to women rather than men (sidebar, \#16).

It would be useful to children's development to broaden the issue of maternal employment to include both parents, the parents' employers, and children's school guardians. If we recognize that the various contexts that impact on children's lives all bear some responsibility for helping children fulfill their developmental challenges, the question may change from "Should mothers seek employment or not?" to "How can family needs be fulfilled in ways that help children's development to flourish?" Children need physical and emotional availability from their parents. Children need some of this parental availability to be consistent and responsive to their time schedules, not an employer's. Children of this age have emerging needs for autonomy. And finally, they need adult monitoring for safety. The range/extent of such requirements varies with age and developmental status, gender, and individual differences demonstrated across children. Within some constraints posed by these parameters, it is clear that children living with mothers who work full-time and children living with mothers who are not employed do not simply manage, but thrive.

Reframing the ownership of responsibility for children's development has numerous implications. Examples follow.

\section{“Family-friendly" work policies}

In contrast to ordinary work-related separations, there exist forms of "extraordinary separations." These include shift work, moonlighting, weekend work, commuter marriages, and job-related travel (sidebar, \#17). Workrelated separations need not have negative effects, but extended, inflexible, or unpredictable work absences may be problematic; the effects of these problematic separations need greater attention by employers and researchers.

Workplace policies are needed that recognize the importance of accommodating school-age children's needs for occasional physical access to their mothers. Both access by phone and the ability of a parent to leave a place of employment occasionally appear to have a positive impact on children's well-being in school and at home (sidebar, \#18).

\section{"Family-friendly" school policies}

Parental involvement at the school site is an important aspect of the home-school relationship. Meetings, class/school performances, school site council meetings, and school assemblies / field trips could be scheduled with employed parents' availability considered.

Rather than assigning homework that puts mothers in the role of taskmaster, it would be more beneficial for teachers to assign homework involving the student and mother in pleasurable shared activities. This change would benefit academic and social adjustment at school among children whose mothers work full-time.

School hours; on-site, after-school programs, and other adult- supervised programs need to be coordinated with parents' work hours to be truly beneficial to children and their families.

\section{"Child-friendly" family policies}

Parents who seek employment need to make sure they balance the financial and personal rewards of their jobs with the costs of less physical and emotional availability to their children. This might mean adjustments in work to accommodate their child's needs; these adjustments might be costly in terms of reduced financial rewards and self-esteem obtained from full commitment to employer needs. Similarly, parents who do not seek employment need to examine the basis for their self-esteem and determine if their children are being made to pay them back in ways that are costly to child development.

Family friends and relatives who can provide school-age children with additional physical, emotional, and supervisory support can help parents establish a crucial link between family, school, and home in ways that benefit developing children.

\section{After-school care}

Children's actual experiences of their after-school care arrangements must be obtained and considered valuable. The same after-school program may be a wonderful, socially supportive experience for one child and an isolating, distressing experience for another. A list of activities and adultchild ratios are not sufficient criteria for determining the value of a particular after-school arrangement. Children need to welcome the option of the after-school care arrangement.

Opportunities for adult monitoring of the child's whereabouts and wellbeing are needed throughout the school years, even when self-care or after-school arrangements are made.

B. Bryant is Professor of Human Development and Family Studies, Department of Applied Behavioral Sciences, UC Davis. Financial support for this report was provided by the Agriculture Experiment Station, UC Davis, as part of the Western Regional Research Project (W-167). 